\title{
Trung tâm ISR tiếp tục hợp tác dài hạn với Viện Toán Cao cấp VIASM
}

Trung tâm ISR (01-09-2021; https://isr.phenikaa-uni.edu.vn /vi/post/tin-tuc/tin-tuc/sub-tin-tuc/trung-tam-isr-tiep-tuc-hoptac-dai-han-voi-vien-toan-cao-cap-viasm) - Ngày 31 tháng 8 năm 2021 vừa qua, Viện Nghiên cứu cao cấp về Toán (VIASM) đã chính thức gửi lời mời hợp tác với vai trò Cộng tác viên lâu dài tới TS. Vương Quân Hoàng-Giám đốc Trung tâm Nghiên cứu Khoa học Xã hội Liên ngành ISR, Trường Đại học Phenikaa.

Từ giữa năm 2017, GS. Ngô Bảo Châu và TS. Vương Quân Hoàng đã cùng thảo luận các ý tưởng cho dự án "Phát triển bộ cơ sở dữ liệu khoa học ngành toán của Việt Nam.” Đến đầu năm 2020, dự án mới chính thức được triển khai. Trong giai đoạn này, nhóm nghiên cứu Trung tâm ISR và VIASM thường xuyên họp mặt để trao đổi các vấn đề liên quan tới CSDL SciMath.
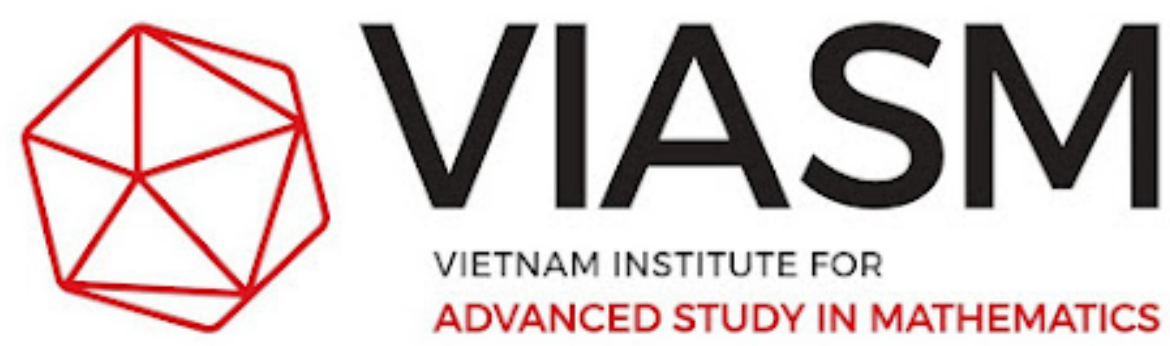
ADVANCED STUDY IN MATHEMATICS

Các kết quả sơ bộ từ CSDL SciMath đã được trình bày trước Hội đồng Khoa học VIASM vào ngày 13-11-2021. Sau đó, báo cáo kỹ thuật "Dự án Phát triển bộ cơ sở dữ liệu khoa học ngành toán của Việt Nam: Một số kết quả sơ bộ ban đầu từ CSDL SciMath" đã được giới thiệu tới công chúng. Hiện tại, đội ngũ xây dựng CSDL SciMath đang cố gắng hoàn thiện để có thể giới thiệu SciMath rộng rãi tới công chúng.

Bên cạnh dự án SciMath, các thành viên Trung tâm ISR cũng đã tham gia thuyết trình tại Seminar Thống kê Ứng dụng T8.2021 do VIASM tổ chức. Ngày 4-8-2021 vừa qua, NCS. Nguyễn Minh Hoàng đã có bài giảng "Bản hòa tấu dữ liệu xã hội” trên nền tảng Zoom với hơn 110 người tham dự.

Tiếp tục quá trình hợp tác đó, TS. Vương Quân Hoàng sẽ chính thức trở thành Cộng tác viên lâu dài của VIASM trong nhiệm kỳ 2021-2024. Hiện tại, dự án SciMath sẽ là công việc trọng tâm của TS. Vương Quân Hoàng và VIASM. 


\section{Tài liệu tham khảo:}

VIASM. (2020). Lễ ký kết thỏa thuận hợp tác giữa Viện Nghiên cứu cao cấp về Toán và Quỹ Đổi mới Sáng tạo Phenikaa. VIASM. URL: https://viasm.edu.vn/hoat-dong-khoa-hoc/tin-tuc/chi-tiet/le-ky= ket-viasm-va-phenikaa

Huyen, N. T. T. (2020). ISR trình bày CSDL ngành toán tại Hội đồng Khoa học VIASM. Centre ISR. URL: https://isr.phenikaauni.edu.vn/vi/post/tin-tuc/tin-tuc/sub-tin-tuc/isr-trinh-bay-csdlnganh-toan-tai-hoi-dong-khoa-hoc-viasm

Chau, N. B., Hoang, V. Q., Phuong, L. V., Hoa, L. T., Ha, L. M., et al. (2020). The 80-year development of Vietnam mathematical research: Preliminary insights from the SciMath database on mathematicians, their works and their networks. arXiv preprint; arXiv:2011.09328.

ISR. (2021). Đại diện Trung tâm ISR thuyết trình tại seminar do VIASM tổ chức. Centre ISR. URL: https://isr.phenikaa-uni.edu.vn /vi/post/tin-tuc/dai-dien-trung-tam-isr-thuyet-trinh-tai-seminardo-viasm-to-chuc

Vuong, Q. H. (2018). The (ir)rational consideration of the cost of science in transition economies. Nature Human Behaviour, 2(1), 5 .

Vuong, Q. H. (2019). Breaking barriers in publishing demands a proactive attitude. Nature Human Behaviour, 3(10), 1034.

Vuong, Q. H. (2020). Reform retractions to make them more transparent. Nature, 582(7811), 149.

Vuong, Q. H., et al. (2018). An open database of productivity in Vietnam's social sciences and humanities for public use. Scientific Data, 5(1), 1180188. 